\title{
Quality of life measurement in patients with oesophageal cancer
}

\author{
J M Blazeby, M H Williams, S T Brookes, D Alderson, J R Farndon
}

\begin{abstract}
Quality of life (QOL) measurement may aid decision making in the treatment of patients with oesophageal cancer but must be clinically valid to be useful. This study considered if the European Organisation for Research and Treatment of Cancer QOL questionnaire, the QLQ-C30, showed differing results in two clinically distinct groups of patients with oesophageal cancer and also investigated the correlation between dysphagia grade and various scales of QOL. Patients treated by oesophagectomy reported significantly better physical, emotional, cognitive, and global health scores than those in the palliative treatment group. Patients who received palliative treatment had significantly worse pain, fatigue, appetite loss, constipation, and dysphagia. The correlations between dysphagia grade and each of the QOL scales and items in both groups of patients were poor. This questionnaire differentiates clearly between the two clinically distinct groups of patients, but to be an entirely appropriate indicator of QOL in patients with oesophageal cancer, an additional specific oesophageal module including a dysphagia scale is required.
\end{abstract}

(Gut 1995; 37: 505-508)

Keywords: quality of life, oesophageal cancer, dysphagia.

The treatment of oesophageal cancer is controversial and poses an important therapeutic challenge. About $50 \%$ of patients will have resectable disease, rendering them suitable for potentially curative surgery. ${ }^{12}$ These patients face a $5 \%$ perioperative death risk, morbidity rates in the region of $10-30 \%$, and an overall five year survival between 10 and $36 \% .^{2-5}$ The role of major surgery in patients with advanced disease is questionable, although it is widely held that an increase in survival may be achieved by this aggressive approach. ${ }^{6}$ Those deemed inappropriate for surgical resection may be palliated by a variety of endoscopic procedures, radiotherapy or chemotherapy. Survival is often poor in these patients, averaging between three and five months. ${ }^{78}$ Because of the morbidity and mortality associated with any of these interventions, both quantity and quality of survival after treatment must be important. Most authors concentrate on death rates and morbidity data as key outcome measures, ${ }^{45}$ but a growing body of opinion considers that a measure of the broader effects of ill health and treatment on the patient's quality of life (QOL) is necessary. ${ }^{9-11}$

Although there is no strict definition of the elements that contribute to health related QOL it is generally accepted that they include physical, social, and psychological aspects. ${ }^{12} 13$ Few studies have examined these wider issues in patients with oesophageal cancer and many have presumed that the commonest presenting symptom, dysphagia, is the overwhelming influence on the patient's QOL. ${ }^{141415}$ One of the best validated measures of QOL in patients with cancer is the European Organisation into Research and Treatment of Cancer (EORTC) core questionnaire, QLQ-C30, a generic instrument designed for international clinical oncology trials. ${ }^{16}$ Results of its use in patients with a heterogeneous diagnosis of cancer have been reported, ${ }^{17} 18$ but it is not known whether this self completion instrument is applicable to patients with oesophageal cancer, as there are currently no data available about its use in this group of patients, neither does it contain questions regarding difficulty with swallowing.

This study therefore had two objectives: the evaluation of the EORTC QLQ-C30 questionnaire as an appropriate QOL measure for patients with oesophageal cancer and an assessment of the correlation between QOL scales and dysphagia grade.

\section{Methods}

Patient details

Seventy seven consecutive patients were treated for oesophageal cancer in a 12 month period beginning August 1993. Forty underwent oesophagectomy and 37 received palliative treatment. Eight patients died within 30 days of intervention, four in each group. Ten patients were excluded (three postoesophagectomy, seven post-palliative treatment) because they were unable to understand and therefore complete the questionnaire, as a result of mental confusion or medicinal side effects. The remaining 59 patients (33 postoesophagectomy and 26 post-palliative treatment) were visited at home and asked to complete the EORTC QLQ-C30 questionnaire. The interviewer (JMB) sought the answers to any omitted questions to avoid missing data. Three patients from the oesophagectomy group and 12 patients in the palliative treatment group required some prompting and clarification from the researcher to complete the questionnaire.

Patients underwent oesophagectomy if they were fit for surgery and there was no pre-operative evidence of distant metastases (group 1).

\author{
Correspondence to: \\ Miss J M Blazeby, University \\ Department of Surgery, \\ Bristol BS2 8HW. \\ Accepted for publication \\ 24 February 1995 \\ of Surgery, Bristol \\ J M Blazeby \\ J R Farndon \\ Department of \\ Epidemiology \\ Medicine, University \\ of Bristol BS8 2PR \\ M H Williams
}


TABLE I Details of patients in the oesophagectomy group, group 1 and patients in the palliative treatment group, group 2

\begin{tabular}{lll}
\hline & $\begin{array}{l}\text { Group 1 } \\
(n=33)\end{array}$ & $\begin{array}{l}\text { Group 2 } \\
(n=26)\end{array}$ \\
\hline $\begin{array}{l}\text { Median age (interquartile range) } \\
\text { Sex (male/female) }\end{array}$ & $\begin{array}{l}64(62-76) \\
\text { Tumour histology }\end{array}$ & $\begin{array}{l}72(68-79) \\
16 / 10\end{array}$ \\
$\quad \begin{array}{l}\text { Adenocarcinoma } \\
\text { Squamous cell carcinoma }\end{array}$ & 19 & 15 \\
Metastases & 14 & 11 \\
Medical problems & 1 & 16 \\
Social class distribution & 2 & 13 \\
$\quad$ I \& II & 10 & 5 \\
III & 11 & 10 \\
$\quad$ IV \& V & 12 & 11 \\
Median follow up in weeks & $16(10-24)$ & $14(4-24)$ \\
(interquartile range) & 3 & 12 \\
Help with questionnaire & & \\
\hline
\end{tabular}

Other patients underwent intubation alone or in combination with radiotherapy (group 2). This preselection produced two clinically distinct groups (Table I). In group 1 patients were younger, only one had known evidence of metastases at the time of the interview, and two had severe co-morbid disease. In group 2, 16 had metastases and 13 severe cardiorespiratory illnesses. Both groups were similar in sex and social class distribution. The assessments were carried out at similar times after intervention: group 1 median 16 weeks (interquartile range 10 to 24 ) and group 2 median 14 weeks after intervention (interquartile range 4 to 24 ).

\section{Quality of life assessment}

The EORTC QLQ-C30 core questionnaire incorporates five functional scales, a global health scale and three symptom scales, each containing between two and five items. Six single items assess additional symptoms commonly found in patients with cancer, as well as the perceived financial impact of the disease and treatment. For all questions, patients are asked to respond in terms of how they were feeling during the previous week. Further methodological details underlying the construction of this questionnaire are described elsewhere. ${ }^{19-21}$ Scoring algorithms have been produced by the EORTC Quality of Life Study Group. All scale and item scores are linearly transformed such that scales range from 0 to $100 .{ }^{16}$ In the functional scales a high score is equivalent to better function, whereas in the symptom scales and single items a high score means more symptoms.

\section{Dysphagia}

The interviewer graded the patient's swallowing over the previous week, on a scale of 0 to 4 :

TABLE II Median scores and interquartile ranges of functional and global health scales

\begin{tabular}{lllll}
\hline & $\begin{array}{l}\text { Group } 1 \\
(n=33)\end{array}$ & $\begin{array}{l}\text { Group } 2 \\
(n=26)\end{array}$ & $\begin{array}{l}\text { Median difference } \\
(95 \% \text { CI) }\end{array}$ & $\begin{array}{l}p \text { Value } \\
\text { (Mann-Whitney) }\end{array}$ \\
\hline Function scales & & & & \\
Physical & $60(40-100)$ & $40(20-60)$ & $20(20$ to 40$)$ & $0 \cdot 001$ \\
Role & $50(0-100)$ & $50(0-50)$ & $0(0$ to 50$)$ & $0 \cdot 068$ \\
Emotional & $92(67-92)$ & $62(33-75)$ & $25(8$ to 41$)$ & $0 \cdot 002$ \\
Cognitive & $83(83-100)$ & $50(33-67)$ & $33(17$ to 50$)$ & $<0.001$ \\
Social & $67(33-83)$ & $42(17-67)$ & $16(0$ to 33$)$ & $0 \cdot 186$ \\
Global health & $50(33-67)$ & $29(17-42)$ & $17(8$ to 33$)$ & $0 \cdot 004$ \\
\hline
\end{tabular}

High score $=$ better function. $\mathrm{CI}=$ confidence intervals.
$0=$ normal food intake, $1=$ difficulty with swallowing some solids, $2=$ able to swallow only soft food, $3=$ able to swallow liquids only, $4=$ complete dysphagia. These scores were linearly transformed to range from 0 to 100 such that dysphagia results could be compared more easily with the QOL scales.

\section{Statistical analysis}

The differences seen between the two groups were examined using the Mann-Whitney U test. Spearman rank correlation coefficients examined any linear association between dysphagia grade and QOL scales in each group of patients. Because multiple significance testing was used, only a $p$ value less than 0.01 was classed as representing a significant difference. ${ }^{22}$

\section{Results}

\section{Quality of life}

Of the 59 patients available for the study there was a $100 \%$ response. The median scores and interquartile ranges of the functional and the symptom scales and items in both groups are shown in Table II and III respectively. Group 2 reported poorer function and more symptoms than group 1. Statistically significant differences were found between the groups with respect to physical, emotional, and cognitive functioning scores $(\mathrm{p}<0 \cdot 01)$. Patients in group 2 who had received purely palliative treatment reported significantly worse global health scores than those in group $1(p<0.01)$ and significantly worse pain, fatigue, appetite loss, and constipation symptom scores $(p<0 \cdot 01)$.

\section{Dysphagia}

Table III shows that the dysphagia score was statistically significantly higher (worse) in those who had palliative treatment $(p<0.001)$. Tables IV and V show that the correlation coefficients between the dysphagia grade and each functional scale and symptom scale and item were poor for both groups. Dysphagia was not significantly correlated with any of the QOL scales or items at the $1 \%$ level.

\section{Discussion}

The incidence of oesophageal cancer is increasing in England and Wales ${ }^{23} 24$ and a wide variety of potentially curative and palliative treatment options exist. ${ }^{25-30}$ There is currently no clear answer as to the best way to treat this distressing disease and therefore the evaluation of all treatments should include a validated, reliable, and appropriate QOL measure.

This study shows that the EORTC QLQC30 questionnaire is responsive to gross differences in severity of the disease, as, frail patients with metastases reported worse functional and symptom QOL scores than younger patients treated with potentially curative surgery. These differences were statistically significant at the $1 \%$ level in some but not all scales. A larger 
TABLE III Median scores and interquartile ranges of symptom scales, symptom items, and dysphagia grade

\begin{tabular}{|c|c|c|c|c|}
\hline & $\begin{array}{l}\text { Group } 1 \\
(n=33)\end{array}$ & $\begin{array}{l}\text { Group } 2 \\
(n=26)\end{array}$ & $\begin{array}{l}\text { Median difference } \\
(95 \% C I)\end{array}$ & $\begin{array}{l}\text { p Value } \\
\text { (Mann-Whitney) }\end{array}$ \\
\hline \multicolumn{5}{|l|}{ Symptom scales } \\
\hline Pain & $16(0-33)$ & $50(16-66)$ & $-33(-50$ to -16$)$ & 0.002 \\
\hline Fatigue & $33(22-56)$ & $78(33-100)$ & $-33(-56$ to -11$)$ & $<0.001$ \\
\hline Emesis & $17(0-33)$ & $42(0-67)$ & $-17(-50$ to 0$)$ & 0.049 \\
\hline \multicolumn{5}{|l|}{ Single items } \\
\hline Dyspnoea & $33(0-33)$ & $33(33-66)$ & $0(-33$ to 0$)$ & 0.462 \\
\hline Trouble sleeping & $33(0-33)$ & $33(0-66)$ & $0(-33$ to -0.01$)$ & $0 \cdot 118$ \\
\hline Appetite loss & $33(0-66)$ & $83(66-100)$ & $-34(-66$ to -33$)$ & $<0.001$ \\
\hline Constipation & $0(0-33)$ & $33(33-100)$ & $-33(-34$ to -0.01$)$ & $<0.001$ \\
\hline Diarrhoea & $0(0-33)$ & $0(0-0)$ & $0(-0.01$ to 0$)$ & 0.118 \\
\hline Financial impact & $0(0-33)$ & $0(0-33)$ & $0(-0.01$ to -0.01$)$ & 0.713 \\
\hline \multicolumn{5}{|l|}{ Dysphagia grade } \\
\hline Dysphagia & $25(25-25)$ & $50(50-75)$ & $-25(-50$ to -25$)$ & $<0.001$ \\
\hline
\end{tabular}

High score $=$ more symptoms.
TABLE V Spearman rank correlation coefficients $\left(\mathrm{r}_{\mathrm{s}}\right)$ between dysphagia grade and each symptom $Q O L$ scale and item

\begin{tabular}{|c|c|c|}
\hline & $\begin{array}{l}\text { Group } 1 \\
\mathrm{r}_{\mathrm{s}}(p \text { value })\end{array}$ & $\begin{array}{l}\text { Group } 2 \\
\mathrm{r}_{\mathrm{s}} \text { ( } p \text { value) }\end{array}$ \\
\hline Pain & $0.20(0.27)$ & $0.25(0.24)$ \\
\hline Fatigue & $0.26(0.15)$ & $0.30(0.14)$ \\
\hline Emesis & $-0.19(0.28)$ & $0.21(0.30)$ \\
\hline Dyspnoea & $-0.14(0.43)$ & $-0.03(0.90)$ \\
\hline Trouble sleeping & $-0.39(0.02)$ & $0.45(0.02)$ \\
\hline Appetite loss & $0.23(0.20)$ & $0.44(0.03)$ \\
\hline Constipation & $0.20(0.28)$ & $0.22(0.29)$ \\
\hline Diarrhoea & $-0.17(0.33)$ & $-0.14(0.50)$ \\
\hline Financial impact & $-0.18(0.32)$ & $0.21(0.31)$ \\
\hline
\end{tabular}

but a valid and reliable self-completion eating scale may prove a better instrument. It is of interest that the highest negative correlation $\left(r_{\mathrm{s}}=-0.39\right)$, was found in the sleep scale in group 1 and the highest positive correlation $\left(r_{\mathrm{s}}=0.45\right)$ was found in the same scale in group 2 . The positive correlation between dysphagia and difficulty in sleeping in patients undergoing palliation alone may not be surprising, however, the negative correlation after oesophagectomy merits further comment. One explanation might be that patients with a worse dysphagia grade report less sleep difficulty, because regurgitation of intrathoracic stomach contents is prevented by anastomotic narrowing. In general dysphagia was negatively correlated with the functional scales and positively correlated with the symptom scales but a larger study is required to test the strength of the associations.

The EORTC QLQ-C30 questionnaire for patients with cancer has been developed with a modular approach. This strategy allows the core questionnaire to be sufficiently general to permit cross study comparisons. A tumour specific module should provide additional specificity to consider questions of particular relevance in a given clinical trial. ${ }^{16}$ This study has shown that the EORTC QLQ-C30 core questionnaire distinguishes clearly between two clinically distinct groups of patients with oesophageal cancer, but because no correlation was established with dysphagia grade, the patients' predominant symptom, the questionnaire requires extra questions. The addition of a validated oesophageal cancer specific module, as recommended by the EORTC Quality of Life Study Group, should improve its specificity and permit detection of even small benefits accrued from new palliative or adjuvant treatments. Such a module would include not only assessment of dysphagia but additional QOL related problems volunteered by patients with oesophageal cancer.

We would like to acknowledge $\mathrm{Mr} \mathrm{K}$ Jeyasingham, $\mathrm{Mr} \mathrm{C} \mathrm{P}$ Forrester-Wood, and Mr C P Armstrong for allowing us to study their patients.

This paper was presented to the British Society of Gastroenterology in September 1994 (Gut 1994; 35: S8).

Miss J M Blazeby is a Research Training Fellow supported by the Research and Development Directorate, South and West Regional Health Authority.

between dysphagia grade and each functional and globa QOL scale

\begin{tabular}{llr}
\hline & $\begin{array}{l}\text { Group 1 } \\
\mathrm{r}_{\mathrm{g}}(p \text { value })\end{array}$ & $\begin{array}{l}\text { Group 2 } \\
\mathrm{r}_{\mathrm{s}}(p \text { value })\end{array}$ \\
\hline Physical & $-0.35(0.04)$ & $-0.29(0.15)$ \\
Role & $-0.22(0.22)$ & $0.06(0.78)$ \\
Emotional & $0.03(0.87)$ & $0.19(0.36)$ \\
Cognitive & $-0.10(0.59)$ & $-0.12(0.57)$ \\
Social & $-0.30(0.09)$ & $-0.23(0.27)$ \\
Global QOL & $-0.24(0.18)$ & $-0.23(0.27)$ \\
\hline
\end{tabular}

1 Earlam R, Cunha-Melo JR. Oesophageal squamous cell 67: 381-90.

2 Sagar PM, Gauperaa T, Sue-Ling H, McMahon MJ, oesophagus. Gut 1994; 35: 941-5.

3 Salama FD, Leong YP. Resection for carcinoma of the oesophagus. $\mathcal{F} R$ Coll Surg Edinb 1989; 34: 97-100. carcinoma: 1 . A critical review of surgery. Brf Surg 1980; Johnston $D$. An audit of the treatment of cancer of the 
4 Watson A. A study of the quality and duration of survival following resection, endoscopic intubation and surgical intubation in oesophageal carcinoma. Br f Surg 1982; 69: $585-8$.

5 Muller JM, Erasmi H, Stelzner M, Zieren U, Pichlmaier H. Surgical therapy of oesophageal carcinoma. $\mathrm{Br} \mathcal{F}$ Surg 1990; 77: 845-57.

6 Lerut TE, de Leyn P, Coosemans W, Van Raemdonck D Cuypers P, Van Cleynenbreughel B. Advanced esophageal carcinoma. World f Surg 1994; 18: 379-87.

7 Oliver SE, Robertson CS, Logan RFA. Oesophageal cancer: a population-based study of survival after treatment. Br $¥$ Surg 1992; 79: 1321-5.

8 Maunoury V, Brunetaud JM, Cochelard D, Boniface C Cortot A, Paris JC. Endoscopic palliation for inoperable malignant dysphagia: long term follow up. Gut 1992; 33: malignant

9 Fitzpatrick R, Fletcher A, Gore S, Jones D, Spiegelhalter D, Cox D. Quality of life measures in health care. I Applications and issues in assessment. BMF 1992; 305 1074-7.

10 Griffin SM, Robertson CS. Non-surgical treatment of cancer of the oesophagus. Br F Surg 1993; 80: 412-3.

11 Allen-Mersh TG. Improving palliation for patients with gastrointestinal cancer. $B r \mathscr{f}$ Surg 1994; 81: 86 .

12 Troidl H. Quality of life: definition, conceptualization and implications - a surgeon's view. Theor Surg 1991; 6: 138-42.

13 Fallowfield LJ. The quality of life: the missing measurement in health care. London: Souvenir Press, 1990.

14 Karlin DA, Fisher RS, Krevsky B. Prolonged survival and effective palliation in patients with squamous cell carcinoma of the esophagus following endoscopic lase therapy. Cancer 1987; 59: 1969-72.

15 Diamentes $T$, Mannell $A$. Oesophageal intubation for advanced oesophageal cancer: the Baragwanath experience 1977-1981. Br F Surg 1983; 70: 555-7.

16 Aaronson NK, Ahmedzai S, Bergman B, Bullinger M, Cull $A$, Duez NJ, et al. The European Organization for Research and Treatment of Cancer QLQ-C30: a quality of life instrument for use in international clinical trials in oncology 7 Natl Cancer Inst 1993; 85: 365-76.

17 Ringdal GI, Ringdal K. Testing the EORTC quality of life questionnaire on cancer patients with heterogenous questionnaire on cancer patients with
diagnoses. Qual Life Res 1993; 2: 129-40.

18 Osoba D, Zee B, Pater J, Warr D, Kaizer L, Latreille J. Psychometric properties and responsiveness of the EORTC quality of life questionnaire (QLQ-C30) in patients with breast, ovarian and lung cancer. Qual Life Res 1994; 3: 353-64.

19 Aaronson NK, Bullinger M, Ahmedzai S. A modular approach to quality-of-life assessment in cancer clinical trials. Recent Results Cancer Res 1988; 111: 231-49.

20 Aaronson NK, Ahmedzai S, Bullinger M, Crabeels D, Estape J, Filiberti A, et al. The EORTC core quality of life questionnaire: interim results of an international field study. In: Osoba D. Effect of cancer on quality of life. Boston: CRC Press, 1991: 185-203.

21 Aaronson NK, Beckmann JH. The quality of life of cancer patients. New York: Raven Press, 1987.

22 Altman DG. Practical statistics for medical research. London Chapman \& Hall, 1991.

23 Cheng KK, Day NE. Oesophageal cancer in Britain. BMf 1992; 304: 711 .

24 Coggon D, Inskip $H$. Is there an epidemic of cancer? $B M \mathcal{F}$ 1994; 308: 705-8.

25 Araujo CMM, Souhami L, Gil RA, Carvalho R, Garcia JA Froimtchuk MJ, et al. A randomized trial comparing radiation therapy versus concomitant radiation therapy and chemotherapy in carcinoma of the thoracic esophaand chemotherapy in carcinom

26 Szawlowski AW, Falkowski S, Morysinski T, NasierowskaGuttmejer A, Karwowski A, Krawczyk M, et al. Preoperative concurrent chemotherapy and radiotherapy for local-regional and advanced squamous cell carcinoma of the thoracic oesophagus: preliminary results of a pilot study. Eur $\mathcal{F}$ Surg Oncol 1991; 17: 575-80.

27 Kelsen DP, Bains M, Burt M. Neoadjuvant chemotherapy and surgery of cancer of the esophagus. Semin Surg Oncol 1990; 6: 268-73.

28 Orringer MB, Forastiere AA, Perez-Tamayo C, Urba $S$ Takasugi BJ, Bromberg J. Chemotherapy and radiation therapy before transhiatal esophagectomy for esophageal therapy before transhiatal esophagectomy for eso

29 Ellis P, Cunningham D. Management of carcinomas of the upper gastrointestinal tract. BMF 1994; 308: 834-8.

30 O'Reilly S, Forastiere A. New approaches to treating oesophageal cancer. BMF 1994; 308: 1249-50.

31 de Haes JCJM, van Knippenberg FCE, Neijt JP. Measuring psychological and physical distress in cancer patients: structure and application of the Rotterdam symptom checklist. Br f Cancer 1990; 62: 1034-8.

32 van Knippenberg FCE, Out JJ, Tilanus HW, Mud HJ, Hop WCJ, Verhage F. Quality of life in patients with resected oesophageal cancer. Soc Sci Med 1992; 35: 139-45.

33 Loizou LA, Rampton D, Atkinson M, Robertson C, Bown SG. A prospective assessment of quality of life after endoscopic intubation and laser therapy for malignant dysscopic intubation and laser ther

34 Spitzer WO, Dobson AJ, Hall J, Chesterman E, Levi J, Shepherd $\mathrm{R}$, et al. Measuring the quality of life of cancer patients. A concise QL-index for use by physicians. fChron Dis 1981; 34: 585-97.

35 Priestman TJ, Baum M. Evaluation of quality of life in patients receiving treatment for advanced breast cancer. Lancet 1976; i: 899-900.

36 Barr H, Krasner N, Raouf A, Walker RJ. Prospective randomised trial of laser therapy only and laser therapy followed by endoscopic intubation for the palliation of malignant dysphagia. Gut 1990; 31: 252-8. 